\title{
CAUSAL PEER EFFECTS IN FINANCIAL DECISION MAKING
}

\author{
Ana Njegovanović, Krešimir Petar Ćosić
}

Ana Njegovanović

ana.njegovanovic@gmail.com

Krešimir Petar Ćosić

kresimir.cosic13@gmail.com

Article info

Paper category: Review

Received: 23.2.2016.

Accepted: 18.3.2016.

JEL classification: D87, D81 


\begin{abstract}
The research paper connects three key elements from the study (conducted using neural database of experimental asset market that have tested the fundamental mechanisms that generate peer effect, the neural database was measured using functional magnetic resonance imaging (fMRI); Cary Frydman, 2015- University of Southern California-Marshall School of Business) relating to: experimental control in the laboratory of random peer assignment,; neural activity in testing new prediction explaining peer effect and neural activity in the conduct of trade. The methodology used in the research of peer effect relies on the theory of predicting error, the signal which measures changes in anticipation of the net present value which generates new information. Cognitive neuroscience shows that the prediction error is measured in a certain part of the brain known as the ventral striatum. Measuring the potential value gives insights to economists on which factors affecting the subjective utility.

Testing is constructed with 48 patients who were given $\$ 100$ of experimental money and they were given the opportunity to invest in two separate assets in over two hundred experiments. The experiment showed that subjects converted theirfinal portfolio from experimental currency to real dollars using the exchange rate of 5: 1 . In addition to profits from the experiment, subjects were paid a fixed "show-up" fee of $\$ 20$.

There are two difficulties in identifying causal peer effect in economic behavior (Minsk, 1993). Correlated behavior between two representatives may potentially be the engine by common shocks of the peer group or endogenous election in the peer group.

In addition to the prediction that deals with causal peer effect, there have been further developed predictions that generate different mechanisms of peer effects using neural database.

Focus on neural prediction is the neural activity that generates the moment when peers allocation investment is published, respectively the display of "peer decisions". This display is exclusively linked to the processing of information as opposed to considering solutions. This is significant because neuroscience is characterized by neural activity that generates new information in decision making.

Thus, neural prediction is determined by the ventral striatum, which predicts the occurrence of peer decisions. The large part of the literature in social psychology suggests that people have a direct need to follow others, especially manifested in situations where there is no objectively correct action, so the cause of intermediaries used peer action as a social anchor on which it bases its behavior.

Certain dialectical relationship between neuroscience and neurofinance determines a deeper understanding of financial decision making which leads to different results and different cognitive operations. Ourthoughts, although abstract in form, determine procedures of certain neural circuits within our brain. The goal of neuroscience is uncovering these circuits and the possibility of deconstructing complex thought processes in individual components and determine how they integrate into our thought process. The results lead towards the understanding of decision making which shape our future and fate. The market implications, from the aspect of neurofinances, is vital in uncovering deeper knowledge about the effect of
\end{abstract}


emotions and states such as attitudes towards risk, excessive trust, heuristic bias and gender, which finally results in financial decision making on an individual and institutional basis. The implications of fear and corruption in the financial industry can be explained through neurofinance and even give us more choices in the decision process. Social decisions demand an evaluation of costs and benefits for oneself and others. Connected with emotions and caution, the amygdala is involved in decision making and social interactions. The harm caused by the amygdala deteriorates social interaction, while the social neuropeptide oxytocin affects social decisions by changing the function of the amygdala in one aspect.

Empirical research, conducted on a sample of randomly selected subjects who were given identical information, shows that on the basis of the neural database gathered from experimental asset market for testing underlying mechanisms which generate peer effect (Cary Frydman, 2015). Experimental evidence of peer effect in individual behavior of trade and neural data were used for testing of experimental mechanisms generating peer effect. Although the mechanisms which create peer effect in laboratory experiments don't suit the quantitative norm they can ensure settings for probing mechanisms using neural database. The methodology of neurofinance replicates the behavior of trade in laboratory conditions which are robustly found in the field.

\section{Keywords:}

Neuroscience/ neurofinance/mechanisms that generate peer effect 


\section{INTRODUCTION}

The connection in neuroscientific research on the topic of financial decision making is defined by its type; this is why we can define decision making as a logical analysis in situations of undetermined outcome or in the form of a cost benefit analysis. In situations of certainty the probability of the majority of individuals creating a clear defined choice and is relatively high; however, when financial decision making involves a cost benefit analysis with uncertainty, the variability increases as well as uncharacteristic results. The type of process of decision making can lead to different results and different cognitive operations.

Research conducted on the field of neurofinance on the topic of decision making is focused mostly on two sections of the brain which influence decision making that is the nucleus accumbens and septic insula, both parts of subcortical structure of the brain. Specifically, the American scientists Camelia Kuhnen and Brian Knutson (2005) scanned the brains of the participants using functional magnetic resonance imagery (fMRI), while they were making financial decisions. Our social decisions need to evaluate the costs and benefits for ourselves and others. Connected with emotions and caution, the amygdala is involved in decision making and social behavior. Signals from the amygdala for rewards and punishments are identical to facial expressions and observing others. The damage caused by the amygdala ruins social interactions and the neuropeptide of oxytocin influences social decisions and partially changes the functions of the amygdala.

The primary mechanisms of trade models on the financial market don't allow investors social interactions with others, they boil down to beliefs and decisions through market prices (Hirshleifer and Teoh, 2009). Research conducted in the past 15 years has shown that social interactions significantly influence financial decisions in different situations. Peers can influence the participation in the stock market (Hong et al., 2004; Brown et al., 2008; retirement savings decisions, Duflo and Saez, 2003; managing the selection of shares of common stock, Hong et al, 2005; and individual investors make decisions about trading, Ivkovic and Weisbenner, 2007; Bursztyn et al., 2014).

Research conducted on the topic of understanding the mechanisms of peer effect in investment decisions (Cary Frydman, 2015) points towards a causal relation. However, there are two channels through witch peer effect can influence decision making. Firstly, the agent can learn the basic values of assets from the peer's decision and therefore the information channel, and second the resulting decisions of a peer can directly enter a functional benefit to another intermediary, therefore a preferential channel. Yet there is one typical mechanism behind the information channel, updating beliefs through Bayes rules - there are variations in a series of competitive mechanisms within the class of preferences that are fundamental to explaining peer effect. This can be explained by example; the investor may affect its peer as it is concerned about social status, or because there is an aversion to inequality. 
The neural activity measured using functional magnetic resonance imaging (fMRI), is used directly to measure interest in relative wealth in the dynamic environment of investment. Although a review of data can be effective in the measurement of subjective wealth (Luttmer, 2005, Card et al., 2012), neural data can directly measure the moment when the relative change in wealth, devoid of potential bias, guides self-reference. Neural information in experimental measurements gives rise to new tests of functional forms of utility over relative wealth. This significance is reflected in the prediction model of asset prices where the investor has a preference for the status that critically depends on the curvature of utility investors face over the relative wealth (Russanov, 2010). Neural database allows the launch of basic tests of concave and convex functions by taking advantage of time-series variation in the relative changes in wealth, during the experiment with functional magnetic resonance imaging (fMRI). Measuring neural activity was based on data collected throughout the brain through fMRI of blood, which is the amount of oxygen in the brain.

Analysis of trading in an environmentusing neural database circumvent obstacles in identifying the causes of peer effect. The data was collected in a controlled laboratory environment where the participants were randomly divided into peer groups. This attractiveness enables the researcher to sidestep the problem of identifying where the correlation between two intermediaries' behaviors may be chosen by selecting similar peer groups or common shocks within a peer group (Manske, 1993). This enables the experimenter to control common shocks in peer groups.

The link between the complexity of peer effect is linked to economic literature on relative relationship of wealth and preferences for status based on Dusenberry, 1994, in the field of experimental economics of social settings such as concern about status or aversion to inequality (Falk et al., 2008; Heefetz and Fank, 2010). Other studies rely on subjective richness that is negatively associated with income of peers. (Luttmer, 2005; Card et al., 2012). In literature on asset prices it explains the empirical rules in the aggregate behavior of the stock market and portfolio choices (Abel, 1990; Campebell and Cochrane, 1990; DelMarzo, 2008; Roussanov, 2010). From the point of neurofinances which links neuroscientific research on the contributions of the decision-making process (Lo and Repin, 2002, Kuhnen and Knutson, 2005; Preuschoff et al., 2006); from the aspect of cognitive neuroscience that investigates the neural mechanisms of social preferences (Camerer and Fehr, 2007).

\section{SCIENTIFIC THEORETICAL BASIS ON THE DEVELOPMENT OF NEUROFINANCE}

Our own limits can be known only when we fearlessly enter the area of the unknown. Only relentless analysis of theories, even those that lead us to strange and unfamiliar areas, will give us a chance to get to know the wide expanse of reality. 
Neurofinances are a relatively young scientific field which combines knowledge of neuroscience and finance. High costs in neurofinancial research are associated with tools such as fMRI, PET, MRI, SPECT and other non-invasive techniques of brain imaging, which limits research and therefore has relatively little scientific work which connects the topic of neurofinance.

The processes going in our brains when we make decisions are extremely complex. This is the reason for a short summary of scientific studies in making financial decisions. Decision-making can be to involve memory access, system of values and emotional responses. Often we need to accumulate evidence for and against the different choices that are available to us and to evaluate the possible outcomes and risks and suppress learned responses, and all these processes can take place unconsciously. Some parts of the brain have been identified in the decision-making process including the orbitofrontal cortex and anterior cingulate. Orbitofrontal cortex is responsible for processing, evaluating and filtering information from social or emotional nature. The Anterior cingulate is responsible for the control and selection of appropriate behavior and tracking errors and incorrect answers. The dorsolateral prefrontal cortex indirectly participates in decision-making. It is involved in working memory, planning and flexibility.

The brain is not a computer. The structure of the neurons of the brain is connecting, loose, flexible, interwoven and rich. So, in our minds, we have a magnificent structure that governs our actions and in some way causes awareness of the world around us. The brain can better be described as a self-organizing system. Neuroscience includes not only anatomy and psychological research but also neurobiology, computer science and biochemistry. It is important to point out that in neuroscientific research other disciplines are included; psychology, psychiatry, neurology, social neuroscience and now neuroeconomics / neurofinanes. The brain and nerves in our body are composed of neural cells that are specialized to transmit signals to each other. Neurons contain cytoplasm (fluid) in which are different molecules as well as a nucleus in which DNA is contained. Each neuron can send signals through the axons and receive signals from other neurons dendrites. Basically each neuron has one axon and many dendrites, thus can receive signals from thousands of other cells but only send one signal at a time. The Axon of each neuron extends to other neurons, but the axon does not touch the cell that receives the signal. Between them there is a synapse, a small tiny space. The brain contains about 10 million neurons and about 1,000 trillion connections. As we use our brain we strengthen dependable connections, building each connection easier. This is how memory develops.

The area of the cerebral cortex that is most closely correlated with the ability of thinking is the Prefrontal cortex- PFC. The Prefrontal lobes are located on the front of the brain, at the top of the cortex. This is the most mysterious and the most intriguing part of all the areas in the brain. This golden vault has various functions; awareness, impulse, free will, inner self, strategic decision making, complex thoughts and emo- 
tions, self-control and morals (free will, inner self, morals has physiological terms. Neuro-philosophy studies the connection between free will and neuroscience. Some areas of the human brain involved in mental disorders that may be associated with free will. Some thinkers like Daniel Donett and Alfred Mele emphasize that free will implies many things, among these versions of free will is dualistic and some do not. But different concept of free will are compatible with neuroscientific approach). The Prefrontal cortex seems manages the sequence, structuring and directing behavior, particularly in challenging or new situations. It is believed to mediate in deciding between alternative options, interpretation and modeling of potential future. A healthy prefrontal cortex allows us to resist the attempts of various influences.

The Prefrontal cortex does not communicate directly with the outside world, but it receives information from all parts of the brain. This action is the integration or meeting point as Elkhonon Goldberg neuroscientist said "this is the only part of the brain in which the incoming signals from the body meet with the incoming signals from the outside world." We can conveniently point out that the prefrontal cortex carried out the ideology of the brain, makes important decisions and strikes a balance between opposite impulses and inclinations. Damage to the frontal cortex affects the ability to make good financial decisions.

Neuroscientific research has revealed which parts of the brain respond to rewards and which parts are responsible for motivation. These studies were a sophisticated mix of algorithms and pharmacology. Pictures show that chemicals like dopamine were transferred from neuron to neuron, figuratively speaking as modern robots made calculations. This research has enabled the formation of the scientific field of neuroeconomics / neurofinances.

So the combination of biology, medicine, economics, psychology and engineering allow us to achieve an understanding of the basic processes of the brain and understanding of neurofinances, because financial decisions result in neurophysiological processes including constant re-evaluation on the one hand and statistical problems on the other hand, balancing the different aspects of emotional and mathematical values. Experimental studies have shown the impact of emotions on decision-making. Neurofinances can be defined as the application of neuroscience in investment activities. Experimental area of neurofinances is defined by the application of scientific methods in identifying carriers and modifier of choice behavior. Experimental tools include neuro-imaging and monitoring equipment that are often the tools of choice in such research. By applying neuroscientific research tools, we have insights in biological carriers of decision makers. Neurofinancal research includes: taking the financial risk (excess and aversion); formation of expectations; valuation; presentation of information and updates to the formulation, reference points, and the emotional charge; probability estimation under conditions of risk, uncertainty and ambiguity; cooperation, competition, the crowd and the social impact of the choice. Neurofinancial research of human behavior under conditions of 
risk and rewards identifying correlations with the behavior of a neuron in the brain involved in motivation, emotion, and a reflection-region strategy. Biology can have constructive and detrimental effects on investment decisions.

Andrew Lo, a finance professor at the School of MIT Sloan School of Management, examined the relationship between biology and financial decisions. His work is one of the most intriguing direction in which neuroscience and biology can move into the business world. Some individuals in the market grow better than others which motivated him to explore the possibility that biological differences undermine the differences in capabilities between winners and losers. His results suggest that differences in the market between individuals form small but very useful opportunities for profit. A key area of the brain is an emotional system and especially one that is ruled by fear.

In cooperation with Russian neuroscientist Dmitry Repin, Andrew Lo has measured over the year 2001 the physiological responses of professional brokers. They gathered a group of brokers who worked on the foreign exchanges and the group who worked in one department of a large financial institution in Boston that specializes in global investments. Measurements were collected during working hours lasting 49-83 minutes. The collected data was compared with the specifics of the changes of the market. On that occasion, they used a computer algorithm to extract such events from the market which are traded in foreign currencies (euro, dollar, yen and British pound). The volatility of the market price includes deviations, unlike bid and ask price, reverse price trends and fluctuations and volatility of prices and yields. The study of these two scientists has made another division of the experienced and inexperienced broker to see how experience affects the autonomic reactions to market events. Although the sample was small there was an astonishing correlation between physiological reactions and market trends. The parameter in the strongest correlation, blood pressure, increased in both groups at a time when the market was extremely unstable. Measurement of impermanence is taken as the difference between the maximum and minimum prices in a short time interval and presented as part of the average cost, and is related to the short-term variance mean. Analysis showed that the blood pressure rose before market instability. This shows us that the broker's body reacted in advance to signs that announce major instability manifested by changing the price. This also shows the ability of the brain to perceive the subtle indicators that are not visible from the analysis of price movements.

Later experiments have shown the possibility of emotional state and success in trading. With this approach, they were checking if a certain kind of personality has greater potential to become a good broker. Using standardized tests found a correlation between personality and success in trading was not found, which led to the conclusion that there is no perfect personality for trading on a stock exchange. However, it found the correlation between mood and success in trading, which is not a surprise. People are happy to earn and unhappy to lose. The most important correlation that 
has been discovered is that they are most pronounced in the worst traders. The worst traders allow emotions to obscure their perception and decision-making processes.

Research conducted by John COATES- senior researcher in neuroscience and finance at the University of Cambridge- and his team studied in 2007. the causes of volatility in the stock market. In the sample they took young brokers who dominated the field of trading. Coates and his team took the saliva of 250 mostly young men and found a correlation levels of testosterone which is high in the morning, and their self-confidence which is also high. Good results have indicated that their testosterone levels are increased above expectations. In those moments, the young people felt the intensity and infallibility in their work which has led to risky behavior of trading in buying overpriced stocks. When stocks fall, testosterone levels are back to normal. We can conclude that an enormous amount of testosterone dictates the behavior of traders. Testosterone is a molecule that explains the irrationality, because too much testosterone can lead to disharmony and economic bubbles in the stock market.

Brian Knutson of Stanford University and Camelia Kuhnen, a professor of finance at Northwestern's Kellogg School of Management scanned the brains of investors as they made decisions to buy and sell. Investors with the highest risk, brain scans showed increased activity in the brain nucleus accumbens - part of the brain that lights up, and an increase in dopamine. Studies have also found that increased activity in the second part of the brain when something unpleasant or dangerous happens.

In today's global financial climate, many people are faced with challenges in financial decision-making and their responsibility towards others. Neuroscientists use their research to face this complex problem and neuroeconomics / neurofinance help link biological and social sciences giving an insight into the evolution of decision-making, because it is known that different parts of the brain are activated depending on the possible outcomes of decisions, social cooperation, profit / prize. Chemicals in the brain affect the individual's willingness to believe and also betray when making financial decisions. The brain becomes more active as the size of the expected profit increases, and in humans with the increased risk of financial decisions the insula increases.

Different ways of thinking: perception, reaction to fear, rationality and emotion is based in making complex strategic financial decisions

Between rationality and emotion, there are subtle differences, because rationality implies optimality while emotions are rapid, immediate reactions that are developed through the biological and cultural evolution. Subtle differences between the rational and the emotional could be translated as opposite emotional. This way we get a balance, because each has its place, and it is difficult to predict what will be the right one because it depends on many things. This shows us that we need to be more detailed and precise in thinking about the mechanisms and factors. 
Emotions, especially if they are negative, permeate the whole brain. Different parts of emotions concentrate on different aspects of emotion. Orbitofrontal cortex focuses on reward and punishment, the medial prefrontal cortex is engaged in linking the results and procedures, while the amygdala leads to a variety of relationships with different objects and their emotional significance. These are extremely complex networks that connect these and other areas, and we have a different experience: anger, calmness, happiness, unhappiness. Emotions are somewhat devoid of criteria and can cause changes in many interrelated areas of the cortex and sub cortex. Changing emotional states can be long, short, depending on our minds, which can blur the decision making. Emotions, fear and aversion contaminate our thoughts and therefore our action. So if we rely on the emotions that can lead us astray, because we use a shortcut to the action and thus lead to potential decisions in favor of shortterm pleasure rather than in favor of greater long term benefits.

Individual differences how the brain processes emotions are very important. People express a wide range of emotions; vary in terms of what their emotional baseline. So we have brave, timid, offensive, peaceful, impulsive people. Some of these differences are caused by genes. Genes affect transmitters such as serotonin, which are thought to influence the degree of anxiety, but there is evidence that early childhood experiences can influence which will be the starting values of many emotions. Research indicates that stress leads people react reflexively and think in stereotypes if they are under stress, unlike if they have time to think about a situation in which they are located.

Our susceptibility to a variety of influences has a strong relationship with our brains, and they work depending on our genes. Studies suggest that the functions of the prefrontal areas are significantly affected by genetics. The low level of education, dogmatism, stress and many other factors affect the function of the prefrontal areas, and it all points to the principles of a dualistic black and white thought process.

By using MRI techniques, it has been shown that dopamine is a key transmitter in the decision making process. Although it is not possible to directly measure the level of dopamine in the human brain, but they can be reached via the genetic fingerprint (author entails number/activity of certain proteins responsible for maintaining the homeostasis of dopamine in the synapse can be labeled possession of certain alleles of certain polymorphic genes encoding these proteins). The human genome is composed of DNA that consists of four pairs of complementary nucleic acid- base pairs.

Christian Bucehel, neuroscientist from Hamburg, was measuring using MRI technology the connection between fMRI activity in striatal dopamine system during a gambling game. Buchel created a genotyping of 105 people who participated in the study. He then looked for differences in brain activity which were related to various DAT and COMT genotypes. Dopamine transporter (DAT), the dismantling process is carried out with the help of protein catechol-O-methyl transferase (COMT). As the possibility of wining rose, dopamine activity was stronger. Buchel discovered 
that people with the Val / Val combination of COMT and $10 \mathrm{R}$ form DAT did not have an increased activity of dopamine as a result of the increased chances of a reward (Catechol-O-methyl transferase (COMT, EC 2.1.1.6) is one of several enzymes that break down catecholamine's such as dopamine, adrenaline and noradrenaline. In humans, the catechol-O-methyl transferase COMT protein is encoded by the gene. As catecholamine's regulation is impaired in a number of medical conditions, several pharmaceutical drugs targeted to changing COMT activity, and thus the availability of catecholamine. COMT was first discovered by biochemist Julius Axelrod in 1957) is one of several enzymes that break down catechol amines such as dopamine, adrenaline and noradrenaline. In humans, the catechol-O-methyl transferase COMT protein is encoded by the gene. As catecholamine's regulation is impaired in a number of medical conditions, several pharmaceutical drugs targeted to changing COMT activity, and thus the availability of catecholamine. COMT was first discovered by biochemist Julius Axelrod in 1957. In simple terms the men were insensitive to risk. These implications are important in the decision making process, especially in decision-making within the group. These genetic variations associated with lower dopamine activity resulting from brain activation levels. If the relative insensitivity to dopamine causes these individuals risky behavior if the potential rewards do not monitor the level of risk, then it is possible that the increased risk starts to choke the brain with dopamine. Such people live of risk and are immune to the effect that fear has on the decision-making processes. The development of science can allow us to cost effectively find out in which of these categories belong we belong to. It can help us in the future in the drafting of the working group that can diversify the genetic portfolio. Our social interaction and our cultural context shape us and our ideas to a greater extent than we are aware.

\section{EMOTIONS; TOP OF INTEGRATED DEGISION-MAKING}

Emotions could be defined as painful or unpleasant feelings that trigger the brain. Neuroscientists have found areas of the brain and brain secretions that are directly associated with emotions including the trading decision makers in given situations (area neurofinance). Decision-making is the core of stock management. It has rational components and emotionality of man.

In addition to technical skills and economic competencies that are important for shareholders and stock traders, the key factor is man. Most stock traders have a very good foundation of knowledge in the economic factors involved in stock trading. Little or no attention is given to the fact that human beings are emotional beings and that emotional intelligence is a factor in most trading, especially when a lot of the time trading is done with a horde mentality.

Basis of Neuroscience / Emotions. Emotions are omnipresent and important for how one sees the world that it becomes necessary to display emotion in a new 
way to explain it scientifically. As such every emotional response, from love to hate and fear to joy, and everything in between, can be summed up (though not quite) as a purely physiological reaction to events in the environment that serve as motivation, away from harm to the prize. Although this is a pretty bold statement, it allows us to look objectively and observe emotional reactions on a purely neurological level.

In the brain, emotions can often be considered more base impulses that come from the inner middle parts of the brain, which is contrary to reasoned and advanced computing higher cortex. Although this model is not entirely wrong, it is important to recognize how closely supposedly 'rational' cognitive processes colored by an emotional experience. Thoughts and comprehension even on a cortical level are often rooted in emotional experiences, in the sense that, for example, while discussing the place of law and morality in civilization might seem like a completely separate and cortical functions that have never experienced emotional reactions such as pain or frustration judgments about what constitutes right and wrong has become impossible to make. That is the story of emotions in the brain, as a cross between the lower 'feeling' aspect, and the top 'conscious' aspect.

Regardless of an automatic behavior, human beings are not only cold automatic beings. Emotions are carriers of actions / activities. On the other hand, too strong emotions lead to people expressing excessive pain or excitement, which can trump over rational thinking and wisdom, influence perception, presentation and decision-making. Neuroscience has brought different conclusions about the "primacy of emotion" in many decisions, primarily on decisions related to money. Therefore, emotions can be useful but also harmful to traders. So, they need to check what emotions take part in decision-making and whether this will lead to rational / efficient attitudes, choices, and behavior or bias in the behavior. Methods which include a "reality check" (prefrontal cortex) and internal chemical secretions can lead to the primacy of emotion that can help against cold and unemotional thinking (Dr. Kaisa Hytonen, Finish Aailto University, 2015).

\section{Biology of the brain}

The dramatic events in the study of the brain and imaging technology rapidly advances our understanding of the human brain. Scientists using brain imaging technology now need only a few hours to assemble the kind of data from a normal human brain that previously took 20 years' inferential work in the lab with nonhuman primates. Furthermore, magnetic resonance imaging can now differentiate neuronal groups that are separated by only one millimeter (Blakeslee, 1993).

Our brain is made up of tens of millions of relatively small basic neural networks, and just like any type of immune antibodies react to a particular antigen of the environment, so that each neural network deals with a very specific element of the outside world- one sound, diagonal line. Various combinations of processes each of 
these networks are very complex phenomena related, of phonemes and triangles to words and pyramids.

So, we have a modular brain, in the sense that it is a relatively small number of standard components that do not think but combine their data to create an incredibly complex cognitive environment. For example, when we look at the red ball rolling on the table, our brain processes color, shape, movement and position of the ball in four separate areas of the brain.

Genetic processes that have evolved over eons created the human brain that is fully equipped at birth with the basic senses / motor parts of a man who needs to successfully operate in the normal physical world. Our kind must hardwire the basic networks for survival (e.g., circulation, breathing, reflexes), but individuals also need flexibility, flexible or soft wired network, so they can respond to the specific challenges of the environment (to learn French or to drive a car).

When we are faced with economic and financial decisions, the question is how our brain functions are activated? Do we know the true underlying financial base of the brain? Is it deliberate? Is this logical? Or is it emotional? We still do not have definitive answers. In recent years we have a new way to look at decision-making on financial markets and risk-taking, are evaluated. Sometimes called neuroeconomics or neurofinance, which seeks to understand and to understand why we made certain financial choices, looking at activity in different parts of the brain, as well as a comprehensive approach to understanding. New discoveries are beginning to question the classical economic assumptions of economic rationality and market efficiency. Our brain seems to be capable of making financial predictions even when we have no knowledge of finance. This understanding of the causes can revolutionize financial modeling.

\section{PEER EFFECT IN MAKING INVESTMENT DECISIONS}

Neural activity was measured by functional magnetic resonance imaging fMRI which allows direct measurement of interest in the relative wealth of dynamic financial environments. This advantage gives us (researcher) a direct measurement at the time when the relative wealth changes without the potential bias that is driven by self-reference, it is necessary to emphasize the investigated data in the measurement of subjective resources as a function of relative gain (Luttmer, 2005; Card, 2012) are also effective. By applying economic theory and neural database to identify the mechanisms that generate peer effect. Neural activity was measured by functional magnetic resonance imaging fMRI which allows direct measurement of interest in the relative wealth of the dynamic financial environment. This advantage provides researchers direct measurement at the time when the relative wealth of changes without the potential bias that is driven by self-reference, it is necessary to emphasize the investigated data in the measurement of subjective resources as a function 
of relative income (Luttmer, 2005; Card, 2012) also are also effective. The distinction between theory and application of neural databases are important in new tests of functional form of the utility over the relative wealth. The model predicted asset price where the investor has the advantage of obtaining the status of relative wealth (Russanov, 2010), neural data runs the basic tests for the concave and convex functions by using time series variation in changing the relative wealth using functional magnetic resonance imaging. Data analysis this approach avoids obstacles in identifying peer effect. The experiment was conducted in strict laboratory conditions where the subjects randomly assigned to the peer group. All information that operators see all data transmitted between the entities thereby enabling control of common shocks in the peer group, excluding the two-part identification designed problems.

The distinction between theory and application of neural databases are important in new tests of functional form of the utility over the relative wealth. The model predicted asset price where the investor has the advantage of obtaining the status of relative wealth (Russanov, 2010), neural data run the basic tests for the concave and convex functions by using time series variation in changing the relative wealth using functional magnetic resonance imaging. Data analysis approach helps us avoid obstacles in identifying peer effect. The experiment was conducted in strict laboratory conditions where the subjects were randomly assigned to the peer group. All information that the subjects see is transmitted between them, thereby enabling control of common shocks in the peer group, excluding the two-part identification designed problems.

In summary, conducted research provides insights into the high standards of laboratory protocols, neural database explains peer effects, observed neural activity is largely consistent with preferences for social status, but is not consistent with direct preferences for conformity or inequality aversion. Subjects showed strongest neural sensitivity to changes in the wealth of the peer which also show the highest peer effects in the behavior of trading. These studies contribute to the understanding of peer effect, because there are few studies that provide insights into the mechanisms of peer effect. We could set aside some authors such as Burstzyn et al., 2014, using an experimental design revealing preferences of investors for risky assets from personal assets at risk. He was able to conclude whether investors bought property due to social information or social usefulness. Both of these mechanisms can be seen as part of a peer effect in line with the data based on neuronal database.

The financial models of trading on financial markets mostly do not allow social interaction and communication with others. Yet in the real world individuals directly observe the behavior of others or learn about decision-making and other beliefs through conversations (Hirshleifer and Teoh, 2009). Empirical data shows that in the last fifteen years, social interactions have a significant impact on financial decision-making in a variety of contexts. This can be an example to show that peers can influence the participation of market shares (Hong et al., 2004; Brown et al., 2008), 
the decision of saving for retirement (Duflo and Saez, 2003; Beshears et al., 2014), management mutual Fund selection shares (Hong et al., 2005; Pool et al., 2014) and the decisions of individual investors (Ivkovic and Weisbenner, 2007; Bursztyn et al, 2014)

\section{SUMMARY}

Based on neuroscientific contribution in financial decision making, neurofinancial scientific theory was developed, where scientists are trying to penetrate the human brain and genetics that are behind the decision-making with tools that give us insights into the structure of the human brain. Research by J. Paulo Vietoa, Armando Freitas da Rocha Fabia T. Rocha on brain activity in making stock investment decisions and how we make financial decisions and many other authors include a complex set of neuroscientific research that provide insights interwoven in human behavior that ultimately lead to financial decisions. Most of academic theory of finance is based on the assumption that individuals act rationally and the behavior of finance treats the selection of investors on the basis of behavioral bias. However, neurofinance unlike the theory of finance tries to understand behavior by testing physiological processes in the brain when exposed to risk, uncertainty and awards. The scientific map of the human mind teaches us how fear and greed carry the financial market. Therefore, neurofinance is important for the future by developing a range of effective tools to improve financial decisions. Neurofinance can develop coherent models including scientific contributions to natural and social sciences.

The mechanisms that generate peer effect by including neural database which were researched by Cary Frydman, 2015 to construct new experimental tests to distinguish between competing preferences that are based on clarifying peer effect (study (conducted using neural database of experimental asset market that have tested the fundamental mechanisms that generate peer effect, the neural database was measured using functional magnetic resonance imaging (fMRI); Cary Frydman, 2015- University of Southern California-Marshall School of Business) relating to: experimental control in the laboratory of random peer assignment,; neural activity in testing new prediction explaining peer effect and neural activity in the conduct of trade.

The experimental results can be summarized:

Peer effect in the individual behavior of trading has been proven, and the neural databases are used for testing between competing mechanisms that generate these peer effects. The brain reacts to the moment when the subject is aware of investment decisions of their peers, because the brain knows how to encode the changes in the expected activities and the usefulness which is consistent with preferences for status. But the measure has limitations in not finding inequality aversion, because aversion to inequality shows a significant interaction with the economic environment in making financial decisions. The models of aversion inequalities that are based on reci- 
procity are important in the financial market that can be judged (Rabin, 1993). In the analysis of the peer effect in competitive settings of financial markets, are likely controlled through preferences for status than the inequality aversion. We conclude that experimental results are reduced to a narrow area of control provided by the laboratory setting. For example, a compilation mechanism for the effect of selective communication between the content of investors about the success or not of the failures leading bias that is closed in the experiment for making investment decisions of each entity in the social treatment and it is unconditionally sent to its peer. The question is to what degree of laboratory experiments are credible to the external real world. Of course, the sample taken measurements using functional magnetic resonance imaging are relatively small, which is a common criticism of neurofinance. Yet despite the shortcomings and partial access to investment decisions, the essence of this research relies on understanding the mechanisms of peer effects on which there is little information and research and a lot of unknowns in the methodology itself. 


\section{REFERENCE:}

Adolphs, R., et al., "Fear and the human amygdala", The Journal of Neuroscience, 15 (1995): 5879-91

Adolphs, R., Tranel, D., \& Damasio, A. R., "The human amygdala in social judgment", Nature, 393, (1998): $470-474$

Adolphs, R., Tranel, D., Damasio, H., \& Damasio, A., "Impaired recognition of emotion in facial expressions following bilateral damage to the human amygdala", Nature, 372, (1994): 669-672

Ahern, K. et al., "Peer effects in risk aversion and trust", Review of Financial Studies, forthcoming, (2014)

Allman, J., et al., "The anterior cingulate cortex: the evolution of an interface between emotion and cognition" Ann. NYAcad. Sci. 935 (2001):107-17

Anderson, N. E., \& Kiehl, K. A., "The psychopath magnetized: Insights from brain imaging", Trends in Cognitive Sciences, 16, (2012): 52-60

Armando, F. R., et al. "Neurofinance: How do we Make Financial Decisions" (2013)

Armony, J.L., LeDoux, J.E., "How the brain processes emotional information”, Ann NYAcad Sci, 821, (1997)

Atsak, P., et al., "Experience modulates vicarious freezing in rats: A model for empathy". PloS One, 6, e21855(2011), http://www.pubmedcentral.nih.gov/articlerender.fcgi?artid=313560o\&tool=pmcentrez\&r endertype $=$ abstract, Accessed 29.05.13

Bault, N., et al., "Interdependent utilities: how social ranking affects choice behavior". PLoS One 3(2008):e3477

Bechara, A., et al. "Deciding advantageously before knowing the advantageous strategy", Science 275 (1997):1293-95

Behrens, T.E., et al., "Learning the value of information in an uncertain world" Nature Neuroscience, 10 (2007):1214,-21

Bermudez, M. A., Schultz W., "Responses of amygdala neurons to positive reward-predicting stimuli depend on background reward (contingency) rather than stimulus-reward pairing (contiguity)," The Journal of Neuropsychology,103(3), (2010): 11 $5^{8-} 70$

Berns, G.S., et al., "Nonlinear neurobiological probability weighting functions for aversive outcomes.", NeuroImage 39 (2008):2047-57

Beshears, J., "The Effect of Providing Peer Information on Retirement Savings Decisions", Stanford University and NBER, James J. Choi Yale University and NBER David Laibson Harvard University and NBER Brigitte C. Madrian Harvard University and NBER Katherine L. Milkman University of Pennsylvania May 21, (2012)

Beshears, J., et al., "The effect of providing peer information on retirement savings decisions", Journal of Finance, forthcoming (2014)

Bicchieri, C., "The Grammar of Society: the Nature and Dynamics of Social Norms", Cambridge: Cambridge University Press, (2006)

Bossaerts, M., Bossaerts, P., "Neurobiological studies of risk assessment: A Comparison of expected utility and mean-variance approaches", Cognitive, Affective, and Behavioral Neuroscience, 8, (2008): 363-374.

Bossaerts, P., et al., "Ambiguity in asset markets: theory and experiment" Review of Financial Studies, In press (2009) 
Bourgeois-Gironde, S., "Regret and the rationality of choices". Philosophical Transactions of the Royal Society, B. vol. 365, (2010):249-258

Bourgeois-Gironde, S., Schoonover, C., "Cross-Talks in Economics and Neuroscience", Review of Political Economics, (2008): $35-50$

Bursztyn, L., "Understanding mechanisms underlying peer effects: Evidence from a field experiment on financial decisions", Econometrica 82, (2014), 1273-1301

Cahill, L., et al., "Is the amygdala a locus of "conditioned fear? Some questions and caveats", Neuron, 23 (1999):227-228

Campbell, J.Y., Cochrane, J. H., "By force of habit: A consumption-based explanation of aggregate stock market behavior", Journal of Political Economy 107, 1999): 205-251

Caplin, A. et al., "Measuring beliefs and rewards: A neuroeconomic approach", Quarterly Journal of Economics 125, (2010): 923-960

Card, D. et al., "Inequality at work: The effect of peer salaries on job satisfaction", American Economic Review 102, (2012): 2981-3003

Christopoulos, G., et al., "Neural correlates of expected value, risk, and risk aversion contributing to decision making under risk" The Journal of Neuroscience, In press (2009)

Chung, D. "Cognitive Motivations of Free Riding and Cooperation and Impaired Strategic Decision Making in Schizophrenia During a Public Goods Game" (2013)

Damasio, A. et al. "Somatic markers and the guidance of behavior: theory and preliminary testing", in H.S. Levin, H.M. Eisenberg \& A.L. Benton (Eds.). Frontal lobe function and dysfunction. New York: Oxford University Press, (1991): 217-229

Damasio, A., "The Feeling of What Happens: Body and Emotion in the Making of Consciousness: Harcourt Brace", (1999)

De Martino, B., et al. "The neurobiology of reference-dependent value computation", The Journal of Neuroscience, 12 (2009): 3833-42

De Martino, B., et al., "Frames, biases, and rational decisionmaking in the human brain" Science 313 (2006): 684- -87

Duflo, E., Saez, E., "Participation and investment decisions in a retirement plan: the influence of colleagues' choices", Journal of Public Economics 85 (2002): 121-14.8

Frydman, C. et al., "Using neural data to test a theory of investor behavior: An application to realization utility", Journal of Finance 69, (2014): 907-946

Frydman, C., Camerer, C., "Neural evidence of regret and its implications for investor behavior", Working Paper (2015)

Goense, J. B. M., Logothetis, N. K., "Neurophysiology of the BOLD fMRI signal in awake monkeys", Current Bioligy, 18 (2008): 631-40

Hare, T. A., et al., "Dissociating the role of the orbitofrontal cortex and the striatum in the computation of goal values and prediction errors.", The Journal of Neuroscience, 28(22), (2008): 5623-30

Hare, T. A., et al., "Dissociating the role of the orbitofrontal cortex and the striatum in the computation of goal values and prediction errors", The Journal of Neuroscience, 28 (2008): 5623-30 
Hollerman, J. R., et al., "Influence of reward expectation on behavior-related neuronal activity in primate striatum.", The Journal of Neuropsychology, 8o(2), (1998): 947-63

Ivković, Z., Weisbenner, S., "Information diffusion effects in individual investors' common stock purchases: Covet thy neighbors' investment choices", Review of Financial Studies 20, (2007): 1327-1357

Knutson, B., et al. "Distributed Neural Representation of Expected Value", Journal of Neuroscience 25 (19), (2005): 4806-4812

Kosfeld, M., et al., "Oxytocin increases trust in humans", Nature 435 (704.2) (2005): 673-676.

Kuhnen, C. M., Knutston, "B. Journal of Financial and Quantitative Analysis", Vol. 46, No. 3, Michael G. Foster School of Business, University of Washington, Seattle, Wa, (2011): 605-626

Kuhnen, C., Knutson, B., "The Neural Basis of Financial Risk Taking", Neuron, 47, (2005): 763-77०

LeDoux, J., "The Emotional Brain", New York: Simon \& Schuster, (1996)

Lo, A. W., Repin, D. V., "The psychophysiology of real-time financial risk processing”, Journal of Cognitive Neuroscience, 14, (2002): 323-39

Lo, A. W., Repin, D. V., "The psychophysiology of real-time financial risk processing", Journal of Cognitive Neuroscience 14, (2002): 323-339

Mason, M. F., Dyer, R., and Norton, M. I.” Neural mechanisms of social influence”, Organizational behavior and human decision process, 110, (2009): 152-159

McClure, S. M., et al., "Temporal prediction errors in a passive learning task activate human striatum", Neuron 38 (2003): 339-46

McClure, S., et al., "Separate Neural Systems Value Immediate and Delayed Monetary Rewards", Science, 3०6, (2004): 5०3-507

O'Neill, M., Schultz W., "Risk prediction error coding in orbitofrontal neurons.", The Journal of Neuroscience 33(40), (2013): 15810-4

Paulus, M.P., et al. "Increased activation in the right insula during risk-taking decision making is related to harm avoidance and neuroticism", (2003)

Rolls, E.T., "The Brain and Emotion", Oxford University Press (1998)

Romo, R., Schultz, W., "Role of primate basal ganglia and frontal cortex in the internal generation of movements. III. Neuronal activity in the supplementary motor area.", Experimental Brain Research 91(3) (1992): $396-407$

Romo, R., Schultz, W., "Role of primate basal ganglia and frontal cortex in the internal generation of movements. III. Neuronal activity in the supplementary motor area.", Experimental Brain Research 91(3), (1992): 396-407

Sanfey, A. G., "Social decision-making: insights from game theory and neuroscience", Science 318, (2007): 598-602

Schultz, W., "Updating dopamine reward signals.", Current Opinion in Neurobiology, 23(2), (2013): 22938

Schultz, W., Dickinson, A., "Neuronal coding of prediction errors.", Annual Review of Neuroscience, 23 (2000): $47^{3-500}$

Singer, T., Critchley, H. D., and Preuschoff, K., "A common role of insula in feelings, empathy and uncertainty", Trends in Cognitive Science 13, (2009): 334-34, 
Stallen, M., Smidts, A., and Sanfey, A. G., "Peer influence: neural mechanisms underlying in-group conformity", Frontiers in Human Neuroscience (2013): 7:50

Suri, R. E., Schultz, W., "A neural network model with dopamine-like reinforcement signal that learns a spatial delayed response task.", Neuroscience 91(3), (1999):871-90

Tieu, K.H., et al. "Perirhinal-amygdala circuitlevel computational model of temporal encoding of fear conditioning", Psychobiology, 27 (1999): 1-25, 84

Tom, S.M., et al., (2007) "The neural basis of loss aversion in decision-making under risk", Science 315 (5811) (2007): 515-518

Tversky, A., Kahneman, D., "Judgment under uncertainty: Heuristics and biases", Science 185, (1974): $1124,-1131$

Ullsperger, M., et al., "Conscious perception of errors and its relation to the anterior insula", Brain Structure Functions 214, (2010): 629-64.3

Volz, K.G., et al. "Predicting events of varying probability: uncertainty investigated by fMRI", NeuroImage 19, 2 Pt 1, (2003): 271-280 